\title{
Multimedia Interaktif Sebagai Media Informasi STMIK ASIA Berbasis Flash
}

\author{
Rina Dewi Indahsari ${ }^{1}$, Aditya Tri Istanto ${ }^{2}$ \\ ${ }^{1,2}$ Teknik Informatika, STMIK Asia Malang \\ ${ }^{1}$ rinadewi@asia.ac.id, ${ }^{2}$ addistanto@gmail.com
}

\begin{abstract}
ABSTRAK.
Menyikapi dari kebutuhan STMIK ASIA dalam menyampaikan informasi perkuliahan kepada mahasiswa secara efektif dan ekonomis, serta kebutuhan akan media apresiasi, disusunlah konsep perancangan untuk mengemas bagaimana sebuah multimedia interaktif dapat secara efektif dan ekonomis dalam menyampaikan informasi serta menjadikan salah satu media apresiasi bagi mahasiswa STMIK ASIA.

Proses pembuatan aplikasi ini meliputi pengumpulan data pendukung melalui observasi dan dan studi pustaka. Aplikasi dibuat menggunakan bahasa pemrograman flash (action script 2.0) dengan dukungan database MySQL, sehingga konten dan fitur didalamnya mampu diperbaharui.

Penelitian ini menghasilkan sebuah aplikasi multimedia dengan dukungan audio dan video, dilengkapi dengan sistem database sederhana yang mampu menampilkan informasi dengan lebih menarik, interaktif, dan ekonomis, serta dinamis dan mudah dalam pengolahan data konten dari informasi itu sendiri.

Melihat dari hasil tersebut, maka dihimbau agar menggunakan media visual yang menarik, serta dapat berinteraksi dengan pengguna, agar dapat meningkatkan efektifitas penggunaan multimedia sebagai media informasi.
\end{abstract}

Kata Kunci :animasi interaktif, informasi efektif, media informasi, multimedia interaktif, STMIK ASIA

\section{ABSTRACT}

Responding to the needs of STMIK ASIA in conveying lecture information to students effectively and economically, as well as the need for appreciation media, drafting concepts are designed to package how an interactive multimedia can be effectively and economically convey information and make an appreciation media for STMIK ASIA students.

The process of making this application includes collecting supporting data through observation and literature study. The application is made using a flash programming language (action script 2.0) with the support of the MYSQL database, so that the content and features within it can be updated.

This research produces a multimedia application with audio and video support, equipped with a simple database system that is able to display information more interesting, interactive, and economical, as well as dynamic and easy processing of content data from the information itself.

Seeing from these results, it is urged to use attractive visual media, and can interact with users, in order to increase the effectiveness of using multimedia as a medium of information.

Keyword :interactive animation, effective information, media information, interactive multimedia, STMIK ASIA 


\section{PENDAHULUAN}

Dalam perkembangannya, teknologi informasi telah banyak diterapkan sebagai media penyampaian informasi yang lebih efektif, baik dari segi visual maupun informasi itu sendiri. Berdasarkan temuan riset linguistik, psikologi, antropologi dan ilmu komputer, Anita E. Woolfolk (Parkay \& Stanford, 1992) yang menyimpulkan sebuah skema penyampaian informasi menyebutkan bahwa, "sesuatu yang menarik perhatian akan lebih mudah diingat daripada sesuatu yang tidak menarik." Dalam hal ini salah satu produk dari perkembangan teknologi informasi yang dapat memenuhi kebutuhan akan informasi yang efektif adalah aplikasi multimedia interaktif. Dilihat dari perkembangannya, tentunya berbagai lembaga pendidikan memiliki peluang besar untuk memanfaatkan multimedia interaktif sebagai salah satu dari perkembangan teknologi informasi tersebut, dalam hal ini adalah Perguruan Tinggi ASIA.

Ditinjau dari perkembangan STMIK ASIA dan meningkatnya pendaftaran calon mahasiswa baru, menunjukkan adanya minat yang tinggi dari masyarakat terhadap kemajuan teknologi informasi. Namun sayangnya, minat yang tinggi ini tidak diimbangi dengan penerapan multimedia interaktif sebagai penyampai informasi yang efisien dan efektif, sehingga jumlah mahasiswa baru yang masuk tidak optimal atas pengetahuannya tentang kampus itu sendiri, baik dari sistem perkuliahan dan informasi lainnya yang sangat berpengaruh besar bagi perkembangan mahasiswa itu sendiri kedepannya, serta berdampak secara tidak langsung terhadap perkembangan Perguruan Tinggi ASIA.

Oleh karena itu dengan dibuatnya media informasi dalam bentuk aplikasi multimedia interaktif ini akan saling melengkapi dan menunjang kekurangan dari media informasi yang sudah ada, dan diharapkan mahasiswa baru akan lebih mudah untuk mengakses beberapa informasi penting di STMIK ASIA dengan dukungan fasilitas kampus, dan aplikasi multimedia interaktif itu sendiri, sehingga informasi yang disampaikan jauh lebih efektif, sehingga mahasiswa semakin kreatif dalam mengembangkan kemampuannya, dan aplikasi ini akan selalu berkembang seiring dengan perkembangan kualitas mahasiswa di STMIK ASIA.

\section{PEMBAHASAN}

\section{Multimedia Interaktif}

Multimedia diambil dari kata multi dan media.Multi berarti banyak dan media berarti media atau perantara.Multimedia adalah media yang menggabungkan dua unsur atau lebih media yang terdiri dari teks, grafis, gambar, foto, audio, video dan animasi secara terintegrasi.

Multimedia interaktif adalah penggunaan beberapa media (teks, audio, grafis, animasi, video dan interactivity) yang berbeda dalam menyampaikan suatu informasi atau menghasilkan produk multimedia seperti video, audio, musik, film, game, entertaintment. Bisa juga dikatakan sebagai penggunaan beberapa teknologi yang berbeda yang memungkinkan untuk menggabungkan media (teks, audio, grafis, animasi, video, dan interactivity) dengan cara yang baru untuk tujuan komunikasi.

\section{Media Informasi}

Demikian pentingnnya media informasi pada masa ini, dikarenakan melalui media informasi manusia dapat mengetahui informasi dan dapat bertukar pikiran serta berinteraksi satu samalainnya.Kata media merupakan bentuk jamak dari kata medium.Medium dapat didefinisikan sebagai perantara atau pengantar terjadinya komunikasi dari pengirim menuju penerima (Heinich et.al., 2002; Ibrahim, 1997; Ibrahim et.al., 2001).Media merupakan salah satu komponen komunikasi, yaitu sebagai pembawa pesan dari komunikator menuju komunikan. Sedangkan pengertian dari informasi secara umum informasi adalah data yang sudah diolah menjadi suatu bentuk lain yang lebih 
berguna yaitu pengetahuan atau keterangan yang ditujukan bagi penerima dalam pengambilan keputusan, baik masa sekarang atau yang akan datang. Maka pengertian dari media informasi dapat disimpulkan sebagai alat untuk mengumpulkan dan menyusun kembali sebuah informasi sehingga menjadi bahan yang bermanfaat bagi penerima informasi, adapun penjelasan Sobur (2006) media informasi adalah "alat-alat grafis, fotografis atau elektronis untuk menangkap, memproses, dan menyusun kembali informasi visual".

\section{Penetapan Bentuk Dasar Media Visualisasi}

1. Element Struktural Fisik pixel.

Spesifikasi fisik dari website ini dibuat dalam workspace widescreen 1366x768

\section{Elemen Estetis Visual}

Perancangan multimedia interaktif ini mempertimbangkan unsur-unsur estetika desain dan suara, karena visual dan audio merupakan salah satu hal penting untuk dapat menarik dan mempertahankan pengguna untuk mengakses multimedia interaktif ini.Kesederhanaan dalam pengadaan objek dan tata letak yang disusun dengan penuh pertimbangan membuat multimedia yang dibangun tetap memiliki prinsip tema yang akan diangkat.

\section{Elemen Verbal}

Multimedia interaktif yang dibuat tidaklah menggunakan elemen verbal, dikarenakan tidak adanya komunikasi langsung, yang disediakan hanyalah penyajian informasi.Namun, mempertimbangkan audio yang mendukung visual.

4. Konsep Multimedia Interaktif

Konsep multimedia interaktif secara umum adalah membangun multimedia interaktif yang simple, animatif dan juga dinamis dari segi penyampaian informasi, dan juga open source sehingga dapat dikembangkan dalam penggunaan jangka panjang.

5. Proses Perancangan Multimedia Interaktif

Aplikasi ini dibuat hanya untuk menampilkan informasi secara offline.Hanya dapat dibuka dengan media yang mendukung flash.

\section{Pembahasan Konsep Teknis}

Perancangan Aplikasi Multimedia Interaktif ini terdiri dari 3 tahap, perancangan visual, perancangan audio, dan sistem. Desain aplikasi multimedia interaktif ini mendahulukan penyusunan data dan informasi untuk menemukan fitur yang dibutuhkan oleh Perguruan Tinggi ASIA dalam bentuk multimedia interaktif, di ikuti dengan pengumpulan data yang nantinya menjadi informasi yang akan disampaikan. Tahap ini kemudian dilanjutkan dengan membuat backsound dan sound-effect yang dibuat dengan mengambil sampling langsung dari alat musik, maupun digital sampling. 


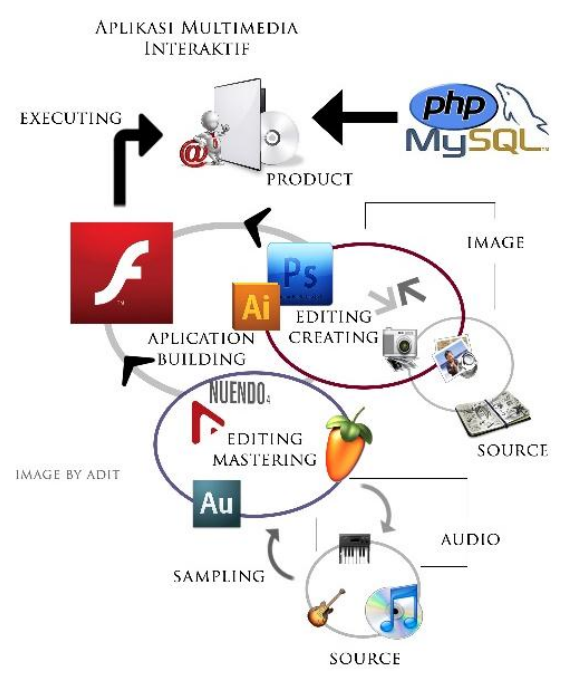

Gambar 1. Alur Teknis Pembuatan Multimedia Interaktif

Tahap lainnya merupakan proses perancangan sistem yang akan digunakan dalam aplikasi tersebut sehingga terintegrasi dengan user- interface yang sudah dirancang pada tahap sebelumnya. Dilanjutkan dengan merancang struktur fitur yang akan digunakan pada aplikasi yang akan dibuat, sehingga nantinya dapat digunakan dan dikembangkan secara optimal dalam jangka waktu kedepan yang cukup lama.

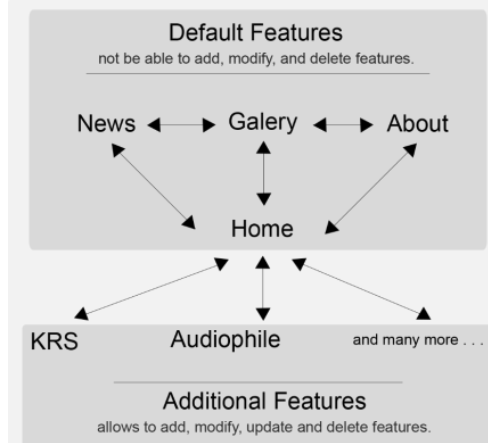

Gambar 2.Features Map Multimedia Interaktif

\section{Menu Utama}

\section{Background}

Background menggunakan gambar gedung kampus pusat STMIK ASIA, yang diambil menggunakan kamera DSLR, dan dilakukan pengolahan lebih lanjut menggunakan AdobePhotoshop, dengan tujuan menghasilkan suasana Menu yang kasual namun tetap tidak meninggalkan suasana aktifitas di kampus.

Menampilkan menu baik default maupun additional yang dapat dilihat dan diakses oleh pengguna. Karena alasan estetis dari kesatuan dengan background yang dibuat, layout untuk menu setiap fitur diposisikan ditengah halaman, berurutan dari sebelah kanan, dimulai dari default features, dan akan bertambah kekiri sesuai dengan jumlah additional features yang nantinya bisa ditambahkan.

\section{Navigasi}

Navigasi yang ada pada halaman ini diantaranya:

\section{- On/off backsound \\ - On/off soundguide \\ - Minimize/maximize}


- Exit

Navigasi di letakkan dalam sebuah dropdown menu yang terlihat minimalis di sebelah tengah atas, muncul setelah di-rollover, agar tidak menganggu layout dan tidak memberikan dominasi terhadap menu-menu yang ada ditengah. Untuk membantu user lebih cepat menemukan menu ini,

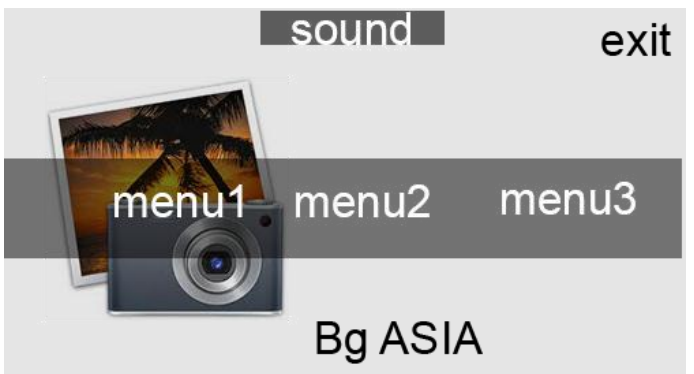

digunakan sound guides pada saat awal aplikasi ini dibuka.

Gambar 3.Thumbnail - Main Menu

\section{Konsep Pemilihan Warna}

Warna yang muncul pada menu ini tidak dibatasi pada warna tertentu, namun digunakan saturasi yang sangat rendah, untuk menguatkan aksentuasi elegan.

Selain elegan, saturasi rendah diharapkan mampu untuk membantu mata tidak cepat lelah dan tidak cepat membosankan, sehingga user mampu lebih lama mengakses informasi yang disampaikan.

\section{Konsep Pemilihan Typografi}

Dari sekian banyak Typeface dengan jenis sans serif, "Hero Light" diputuskan untuk menjadi Typeface utama pada aplikasi ini.Sesuai dengan konsep awal pembuatan aplikasi ini, Typeface "Hero Light" dipilih karena memiliki faktor optis legability dan readability yang baik, konotasi elegan yang kuat namun tidak meninggalkan suasana kasual.

\section{Konsep Animasi}

a. Untuk aksentuasi estetis, digunakan tekstur poligonal yang bentuknya random, skala posisi horisontal dan vertikal yang dianimasikan, bergerak sesuai dengan gerakan pointer mouse, dalam hal ini bergerak berlawanan dengan pinter mouse.

b. Sedangkan untuk keperluan layouting yang baik yang bertujuan untuk memberikan point of interest pada menu utama aplikasi ini, digunakan animasi cahaya didekat menu utama tersebut, dalam hal ini intensitas cahayanya yang dianimasikan.

\section{Konsep Audio}

a. Backsound

Backsound dibuat dengan irama jazz, sedikit techno, dan dilakukan looping agar tercipta suasana yang kasual, kondusif untuk membaca, dan meringankan ukuran file dari multimedia yang dibuat.

b. Soundguides

Soundguides menggunakan suara wanita muda dikarenakan suara perempuan cenderung memiliki artikulasi baik dan range nada yang tepat untuk menyampaikan informasi. Dalam hal ini pembuatan soundguides menggunakan voicegenerator.

News

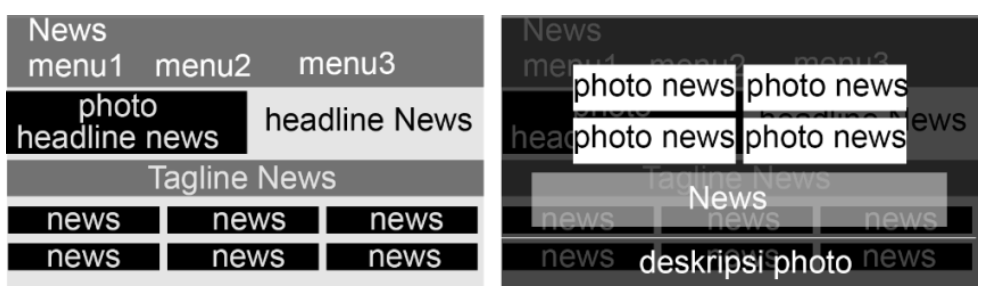


Gambar 4. Thumbnail - News (kiri), deskrpsi news (kanan)

Fitur yang menampilkan berita terbaru, tentang pengumuman akademik, event, dan hal penting lainnya yang bersifat mendadak dan membutuhkan publikasi, baik informasi dari kampus, dosen, maupun mahasiswa.

\section{Headline News}

Karena berisikan tiga buah data pertama yang terakhir kali diupdate, sesuai dengan tujuan sebuah penyampaian informasi, User diharapkan untuk melihat headline news saat pertama fitur news dibuka.

\section{Tagline News}

Konten ini dibuat dengan tujuan untuk menyampaikan informasi singkat, yang membutuhkan waktu cepat dalam penyampaiannya, dan tidak memiliki usia informatif yang lama.

\section{News History}

Konten ini dibuat untuk membantu kemampuan mengingat user, dikarenakan membaca dengan timing yang tidak tepat, atau karena kurangnya konsentrasi, dan hal-hal lain yang menyebabkan informasi tidak tersampaikan dengan sempurna, atau karena ingin membaca dan melihat dengan lebih detail.

\section{Headline News}

Oleh karena headline news diharapkan untuk pertama kali dilihat oleh user, dominasi diperlukan dengan memberikan ukuran yang sedikit lebih besar dari konten-konten lain yang ada pada fitur News, dan diletakkan di posisi paling atas pada halaman ini.

- Elemen Teks

Judul konten diletakkan disebelah kanan atas bodytext, disisi kanan gambar konten. Typeface "Hero Light", letter spacing $1.0 \mathrm{pt}$, line spacing $1.0 \mathrm{pt}$, warna hitam, ukuran $38 \mathrm{pt}$ untuk judul dan $12 \mathrm{pt}$ untuk bodytext. Judul diberi ukuran sedikit besar supaya memudahkan untuk memilih konten yang akan dibaca, tidak menggunakan indent maupun hang-inindent untuk menghemat ruang, juga untuk membantu hal tersebut paragraf menggunakan rata kiri.

- Elemen Visual

Foto diberikan kepada semua berita yang ditampilkan berfungsi untuk menguatkan informasi. Diberikan garis pembatas disebelah atas dan bawah untuk estetika dan pembatas antar kategori berita satu dan yang lainnya.

- Invisible Elemen

Untuk memberi kesan lebar, pada foto tidak diberikan margin, namun pada judul dan bodytext diberikan margin 10 pixel ke kanan dari foto, dan 10 pixel ke kiri dari batas kanan ukuran maksimum aplikasi ini. Sedangkan judul dan Bodytext dipisahkan dengan 5 pixel ruang kosong. Hal ini dilakukan bertujuan untuk estetika dan kenyamanan membaca.

- Sequence

Sequence yang diharapkan adalah foto - judul - bodytext - (kembali ke foto - judul - bodytext) - ataupindah kategori tagline news.

\section{- Emphasis}


Foto diberikan ukuran yang sama dari total ukuran margin judul dan bodytext, yaitu weight $\mathrm{x}$ height $=700 \times 200$ pixel. Sehingga nampak lebih mendominasi dari ukuran total judul dan bodytext.

- Balance

Keseimbangan disini tercapai dari batasan margin, dan ukuran margin dari foto dibanding dengan total ukuran margin judul dan bodytext. (symetrical balance/forma balance).

- Unity

Kesatuan tercapai dari elemen visual yang berupa garis hitam tebal yang membedakan kategori headline dan tagline. Sehingga dapat dibedakan bahwa elemen-elemen yang sudah dijelaskan diatas merupakan satu bagian informasi yang ingin disampaikan.

\section{Tagline News}

Merupakan berita singkat yang butuh disampaikan secara cepat, namun bukan berita utama, sehingga diletakkan dibagian tengah halaman ini, tepat dibawah headline news, diharapkan user melihat segera setelah headlinenews dibaca

- Elemen Text

Judul berada disebelah kiri bodytext. Ukuran judul 38 pt, warna hitam intensitas $80 \%$, letter spacing 2.0, dan untuk bodytext 28 pt warna hitam $100 \%$, letter spacing 2.0 .

- Elemen Visual

Garis pembatas / separator antara judul dan bodytext

- Invisible Elemen

Margin judul weight $\mathrm{x}$ height $=400 \times 37$ pixel, margin bodytextweight $\mathrm{x}$ height $=1366 \times 30$ pixel, kedua margin sejajar tengah horisontal.

- Sequence

Judul - bodytext - (kembali ke judul - bodytext $)$ - atau pindah kategori news.

- Balance

Elemen visual membantu keseimbangan dalam memisahkan bagian kiri dan kanan pada tagline news, yaitu judul dan bodytext. (assimetrical balance/informal balance).

- Unity

Kesatuan dibatasi oleh elemen visual berupa garis tebal sebagai batas pemisah dari kategori headline dan history news. Elemen visual tersebut mampu menegaskan bahwa elemen- elemen yang dijelaskan di atas merupakan satu kesatuan informasi yang ingin disampaikan.

\section{News History}

Diletakkan dibagian paling bawah dari halaman, karena prioritas dibacanya paling rendah, juga karena masih memungkinkan dilihat secara detail sesuai dengan interaksi user terhadap aplikasi ini.

- Elemen Text

Caption berupa Judul dan tanggal informasi muncul pada keenam informasi di kategori ini saat di rollover. ukuran 14pt untuk judul dan $11 \mathrm{pt}$ untuk tanggal. Ketika informasi ini diklik, muncul detail dari informasi tersebut dengan judul berukuran 38pt, tanggal 14pt, dan bodytext 10pt. Ketika keempat gambar dari detail infromasi di rollover 
muncul caption berupa footer menampilkan keterangan dari gambar tersebut berukuran 12pt. Semua font putih dengan intensitas $100 \%$.

- Elemen Visual

Garis tebal pembatas antar kategori informasi, kotak hitam sebagai background ketika informasi pada kategori history dibuka, dan gambar - gambar dari konten yang diupload.

- Invisible Elemen

Margin gambar weight $x$ height $=453 \times 125$ pixel, judul dan tanggal berjarak vertical 5 pixel, bodytext line spacing $1.0 \mathrm{pt}$.

- Sequence

Informasi pertama - detail (judul - tanggal - detail gambar - caption bodytext) - infomasi kedua - detail (judul - tanggal - detail gambar caption - bodytext) - informasi ketiga dan seterusnya.

- Emphasis

Dari keenam informasi yang ditampilkan, tidak diberikan penekanan terhadap ukuran warna maupun bentuk, dikarenakan memiliki prioritas yang sama untuk dibaca.

- Balance

Ukuran semua gambar ditampilkan sama, dengan ukuran tiap font disetiap detail informasi juga memiliki ukuran dan warna yang seragam. (symetrical balance/forma balance).

\section{Konsep Pemilihan Warna}

Fitur ini menampilkan gambar dan tulisan sebagai informasi utamanya. Sehingga diperlukan background yang mampu membantu kemampuan membaca manusia, sekaligus tidak membuat distorsi warna pada gambar. Oleh karena itu putih sampai hitam dengan berbagai intensitasnya dijadikan pilihan.

\section{Konsep Animasi}

Animasi yang digunakan diusahakan tidak terlalu mencolok ditujukan untuk membantu dalam membaca. Sebuah line loading di berikan dibawah konten headline news untuk membantu informasi waktu tayang sebelum berganti ke konten selanjutnya.

\section{Lecturer Galery}

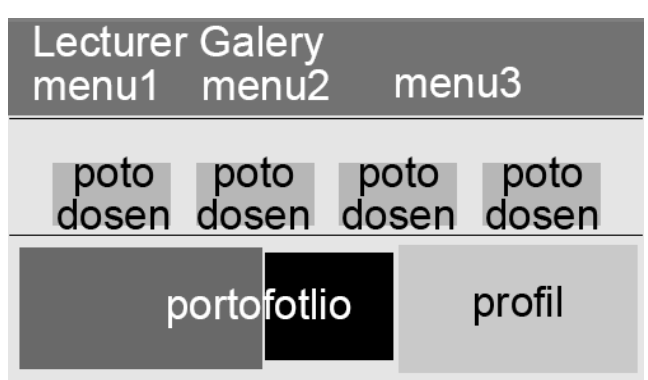

Gambar 5.Thumbnail - Lecturer Galery

Memberikan informasi biodata dosen pengajar di ASIA, seperti nama, foto, nomor telepon, alamat, dan portofolio.Pada fitur ini user diharapkan untuk benar-benar melihat seluruh konten dengan nyaman tanpa prioritas, sehingga tampilan konten pada fitur ini tidak ada yang mendominasi, sedangkan navigasi, backsound dan soundguides sama dengan default features yang lain.

\section{Layouting}


a. Foto Dosen

Peletakkan foto dosen diletakkan di tengah halaman, dengan ukuran yang mendominasi, ditujukan sebagai point of interest saat pertama kali halaman ini dibuka.

b. Portofolio

Portofolio ditampilkan berupa gambar, muncul setelah foto dosen diklik. Diletakkan di sebelah kiri bawah, sesuai dengan kebiasaan dan budaya membaca dari kiri ke kanan. Diikuti dengan deskripsi karya dari portofolio tersebut.

c. Profil

Deskripsi biodata diletakkan disebelah kanan deskripsi portofolio, meliputi nama lengkap, jabatan, email, nomor telepon, dan alamat rumah.

\section{Konsep Pemilihan Warna}

Pada menu ini banyak menampilkan gambar sebagai informasi data utamanya. Karena komposisi warna yang terdapat dalam foto (baik pada profil dan portofolio) pada umumnya beragam, sesuai dengan konsep nirmana dwimatra "dilatasi warna", dibutuhkan sesuatu yang bukan warna untuk meredam kontras dari warna-warna yang berbeda tersebut, dalam hal ini adalah hitam atau putih.

Pada menu ini diputuskan untuk menggunakan dominasi hitam dengan berbagai intensitasnya sebagai dominasi pada background. Tidak dipilih putih dikarenakan hitam lebih mampu untuk memperkuat kontras dan saturasi warna terhadap gambar yang ditampilkan sebagai informasi utamanya.

\section{Konsep Animasi}

Digunakan animasi cahaya yang jatuh dari sisi kiri atas ke arah kanan bawah, dengan intensitas cahaya yang dianimasikan, diberikan untuk keperluan estetika.

About

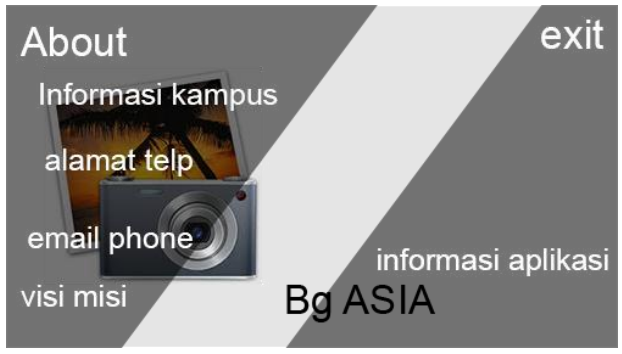

Gambar 6.Thumbnail - about

Menampilkan visi dan misi, alamat, nomor telepon, serta fax STMIK ASIA, juga status serta informasi untuk pengembangan aplikasi ini sendiri.

\section{Layouting}

- Elemen Text

Pada informasi STMIK ASIA Bodytext 11pt putih intensitas $90 \%$ line spacing 1.0pt, line spacing 1.0pt. Signature 11pt putih 100\% untuk judul, dan putih $80 \%$ untuk bodytext. Sedangkan informasi untuk aplikasi menggunakan 16pt putih $100 \%$.

- Elemen Visual

Background foto menggunakan gedung STMIK ASIA.

- Sequence 


\section{Background - bodytext (STMIK ASIA) - signature - bodytext (aplikasi).}

\section{Konsep Pemilihan Warna}

Saturasi rendah untuk tetap mempertahankan aksentuasi saat aplikasi ini pertama dibuka (pada menu home).

\section{Konsep Animasi}

Pada saat pertama menu ini diakses, ditampilkan terlebih dahulu gedung STMIK ASIA, kemudian user dialihkan untuk membaca informasi dengan animasi bidang hitam dari sisi kanan dan kiri menutup sebagian background dengan intensitas hitam 80\%, kemudian textfade in dari intensitas putih $0 \%$ menuju $90 \%$ untuk bodytext, $80 \%$ untuk caption bodytext.

\section{Additional Features}

Aplikasi ini bersifat dinamis, dimana setiap orang dijinkan untuk merubah, menambah, memperbaharui, bahkan menghapusfitur yang ada selain defaultfeature dengan ketentuan dan syarat tertentu.Adapun fitur tambahan yang menjadi satu bundle saat aplikasi ini di-install pertama kali adalah:

\section{Infografis Panduan KRS}

Dengan tampilan sederhana, didukung dengan infografis yang menarik, serta karakter yang berperan sebagai "teman maya" yang sedang melakukan prosedur KRS, user diajak untuk aktif melihat animasi dari prosedur yang berlaku saat itu, diharapkan prosedur KRS menjadi lebih mudah dimengerti dengan penyampaian informasi yang menarik dan tidak membosankan.

Namun jika fitur ini sudah tidak layak untuk disajikan karena informasi yang tidak up to date, maupun karena diberlakukannya sistem yang baru, maka fitur ini memungkinkan untuk dihapus, dimodifikasi, atau diperbaharui karena bersifat open source seperti yang sudah dijelaskan diatas.

\section{Audiophile}

Dengan mengusung konsep visual yang sederhana, fitur ini mampu memberikan apresiasi terhadap mahasiswa yang memiliki kelebihan dibidang seni suara, baik sebagai sound engineering, artist, band, dan seni suara/musik lainnya, sehingga karya yang dibuat dapat diunggah dan memungkinkan orang lain untuk mendengarkan dan mengakses karya tersebut, serta mendapatkan informasi seperti biodata artist, judul lagu, dan informasi lainnya.Namun seperti additional features lainnya, fitur ini memungkinkan untuk dihapus, dimodifikasi, atau diperbaharui, seperti yang sudah dijelaskan diatas.

\section{Grapholic}

Dengan konsep visual sama dengan fitur audiophile, namun memiliki fungsi dan tujuan yang berbeda. Fitur ini mampu menjadi wadah apresiasi bagi mahasiswa maupun dosen yang memiliki satu atau beberapa project yang mampu didokumentasikan dalam bentuk visual/file gambar. Sehingga project tersebut dapat diunggah menjadi portofolio yang bersangkutan dan memungkinkan untuk dilihat oleh orang lain yang mengakses aplikasi ini.

\section{KESIMPULAN}

Aplikasi multimedia interaktif yang dibangun seluruh konten informasinya ditunjang dengan fitur update.Aplikasi ditunjang dengan audio-video yang interaktif.Aplikasi teruji dan mampu beroperasi pada beberapa sistem operasi dan resolusi layar monitor. Aplikasi terintegrasi dengan sistem database. Sehingga memungkinkan untuk digunakan jangka 
panjang, bahkan sangat mungkin untuk peningkatan kualitas dari seiring digunakannya aplikasi ini, karena sistem pengembangan aplikasi yang tidak dikoordinasi oleh suatu individu atau lembaga, melainkan oleh para individu atau pengguna yang ingin bekerja sama mengembangkan aplikasi ini dengan memanfaatkan kode sumber (source-code). Aplikasi ini mampu melengkapi media informasi di STMIK ASIA dan menjadi salah satu media informasi digital yang dinamis di STMIK ASIA.

\section{DAFTAR PUSTAKA}

Ardjaka, S. Metodologi Desain. Malang: Universitas Negeri Malang, 2009.

Hasan, Alwi. Kamus Besar Bahasa Indonesia. Jakarta: P.N. Balai Pustaka, 2005.

Hofstetter, Fred T. Multimedia Literacy Third Edition. New York: McGraw-Hill International Edition, 2001.

Kusrianto, Adi. Pengantar Desain Komunikasi Visual. Yogyakarta: Andi Offset. 2007.

Lubis H, S. Metode Riset Untuk Desain Komunikasi Visual. Yogyakarta: Andi Offset. 2007.

Pujiriyanto. Desain Grafis Komputer (Teori Grafis Komputer). Yogyakarta: Andi. 2005.

Robin, Linda. Menguasai Pembuatan animasi dengan Macromedia Flash. Jakarta: Elek Media Komputindo, 2001.

Rustan, Surianto. Mendesain Logo. Jakarta: Gramedia, 2009.

Rustan, Surianto. Hurufontypografi. Jakarta: Gramedia, 2010.

Rustan, Surianto. Layout Dasar dan Penerapannya. Jakarta: Gramedia, 2010.

Safanayong, Yonky. Desain Komunikasi Visual Terpadu. Jakarta: Arte Intermedia, 2006.

Sihombing, Danton. Tipografi Dalam Desain Grafis. Jakarta: Gramedia, 2001.

Turban., dkk. Aplikasi Multimedia Interaktif. Yogyakarta: Paradigma, 2002.

Vaughan, Tay. Multimedia : Making it Work 6th Edition. Singapore: The McGraw Hill, 2004.

Zam Zami, Ahmad. Pembuatan Lagu Indie Menggunakan Fruity Loop. Yogyakarta: Amikom, 2010 